\title{
Nanoscale Materials Characterization in Industry: Aerosols Produced from Abraded Composite Restoratives
}

\author{
Mary I. Buckett ${ }^{1}$, Axel Bogdan ${ }^{2}$ and Daniel A. Japuntich ${ }^{3}$ \\ 13M Company, Corporate Research Analytical Laboratory, St. Paul Minnesota 55144 \\ ${ }^{2} 3 \mathrm{M}$ Company, Industrial Adhesives and Tape Division, St. Paul Minnesota 55144 \\ 33M Company, Safety, Security, and Protective Services Laboratory, St. Paul Minnesota 55144
}

Nanotechnology has impacted a number of core technology platforms in the manufacturing arena, and has been leveraged to produce game-changing new product opportunities. Commercial manufacturers have introduced engineered nanoparticles (ENPs) into their filler systems to enhance a variety of product properties. For example, $3 \mathrm{M}$ has leveraged the high value nanocomposites bring to the dental industry. Nanocomposites exhibit excellent wear characteristics combined with the high esthetics people expect, thus providing long-lasting, good looking restorations. True nanotechnology in dental composites, i.e. the bottom-up design of nano-size filler particles in the size range 1-100 $\mathrm{nm}$, is being used quite successfully in dental restorative products. ${ }^{(1)}$

Commensurate with nanotechnology implementation, it is important - but difficult - to study whether free engineered nanoparticles (ENPs) can be released from a composite product, for example in the form of airborne dust during mechanical manipulations like drilling or grinding. We've addressed this problem with a methodical approach for generating, collecting, and analyzing nano-size aerosol particles from abraded dental composite materials. ${ }^{(2)}$ Standard aerosol sampling instruments were combined with a custom-made sampling chamber to create conditions of a dental drilling environment. In this experiment, we sampled fresh, steady-state aerosol produced from drilling a dental composite and collected data on aerosol size distribution before significant Brownian coagulation could occur. The aerosol particles were counted and sorted by electrostatic classification into discrete size ranges. Aerosol samples in the $7 \mathrm{~nm}, 20 \mathrm{~nm}$ and $75 \mathrm{~nm}$ range were routed directly onto TEM grids for morphology, size, and compositional analysis by Transmission Electron Microscopy (TEM).

Our test results show that the nano-size aerosol particles produced during the abrasion of dental composite fall into three main categories (in order of prevalence): 1) oil; 2) graphitic carbon or carbon ash; and 3) composite material (ENP + binder). Results from the 3 size categories are summarized in Table 1. During abrasion, aerosol generation seemed independent of the percent filler load of the restorative material and the operator who generated the test aerosol. TEM analysis confirms that 'chunks' of filler and resin are generated in the nano-size range (see Figure 1); however free ENPs are not observed in any of the size ranges we investigated.

\section{References:}

[1]. Mitra, S.B., Wu, D., Holmes, B.N.: An Application of Nanotechnology in Advanced Dental Materials, J Am Dent Assoc 134:1382-1390 (2003)

[2] Bogdan, A., Buckett, M., Japuntich, D.: Nano-Sized Aerosol Classification, Collection and Analysis - Method Development Using Dental Composite Materials, J Occup and Environ Hygiene DOI: $10.1080 / 15459624.2013 .875183$ (2014) 
TABLE I. TEM Analysis Summary of aerosol particulates observed when grinding dental composite materials in a controlled environment.

$\begin{array}{cccccc}\text { Size Range } & \begin{array}{c}\text { Amorphous } \\ \text { Carbon Ash }\end{array} & \begin{array}{c}\text { Graphitic } \\ \text { Carbon }\end{array} & \text { Oil } & \begin{array}{c}\text { Dental Composite } \\ \text { (Filler attached to } \\ \text { Resin) }\end{array} & \begin{array}{c}\text { Free Dental } \\ \text { Filler } \\ \text { Particles }\end{array} \\ 7 \mathrm{~nm} & \text { No } & \text { No } & \text { Yes } & \text { No } & \text { No } \\ 20 \mathrm{~nm} & \text { Yes } & \text { Yes } & \text { Yes } & \text { No } & \text { No } \\ 75 \mathrm{~nm} & \text { Yes } & \text { Yes } & \text { Yes } & \text { Yes } & \text { No }\end{array}$

Figure 1. STEM image at right and $x$-ray elemental map data showing the composition of the bulk agglomerated dental filler composite used in a commercial dental restorative product.

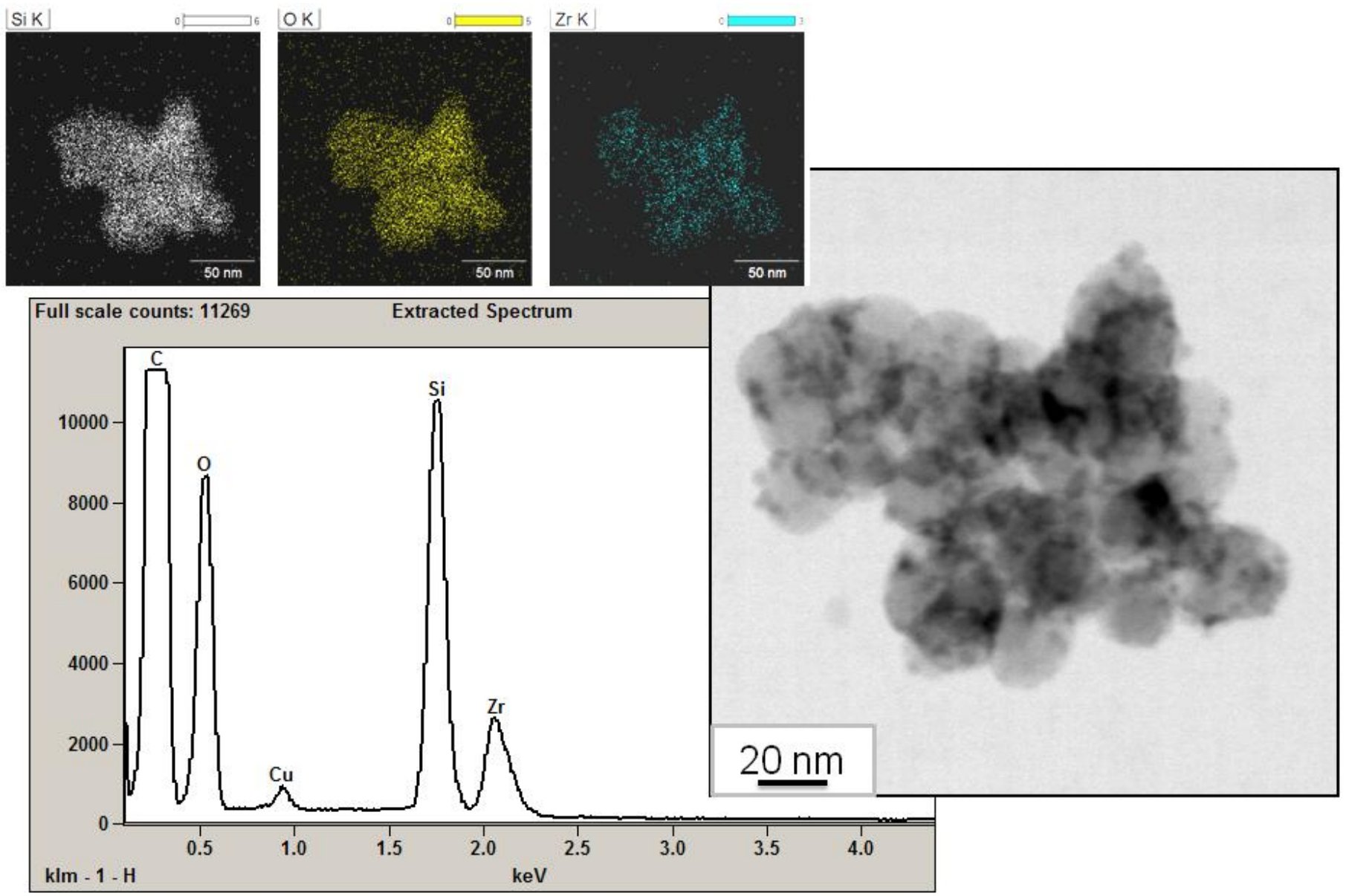

